\title{
Artes Cênicas
}

\section{Pontos de cultura: um espaço para 0 teatro comunitário nas políticas públicas}

Culture points: a space for community theater in public policy

por Márcia Pompeo

\section{RESUMO}

0 presente artigo questiona a viabilidade financeira do teatro comunitário, através de políticas públicas na área da cultura e aponta os Pontos de Cultura como alternativa. 0 teatro feito em comunidades aqui é visto como uma prática artística relacionada com a estética das manifestações culturais da comunidade e/ou com a história dos próprios participantes, que dialoguem com as necessidades e interesses da comunidade. As dificuldades dos grupos teatrais comunitários em ultrapassar a barreira da falta de espaço exigem a criação de alternativas de sustentabilidade. As políticas públicas são aqui caracterizadas como programas governamentais com o objetivo de atenuar os desníveis sociais causados pelo sistema econômico. Os Pontos de Cultura, a partir de seu foco fenomenológico, trazem autonomia de ação às manifestações já existentes, de acordo com cada forma particular de organização, são aqui vistos como uma resposta para a concretização do teatro na comunidade.

Palavras-chave Pontos de Cultura; Políticas Públicas; Teatro na Comunidade

\section{ABSTRACT}

This article questions community theatre financial availability through cultural government policies and points the new concept of Culture Points as an alternative. Community theatre is here as a practice based on the aesthetics of the community culture and /or and the stories of the participants that dialogue with the community needs. The difficulties of the community theatre groups to overcome the barrier of lack of space and financial support require alternatives of sustainability. The public cultural policies are here characterized as government programs aimed at mitigating the social inequality caused by the economic system. The Culture Points, and its phenomenological focus, bringing autonomy of action to existing practices, are understood as an answer to make community theatre possible.

Keywords Culture Points; Public Policy; Community Theatre 


\section{Introdução}

0 teatro realizado em comunidades tem características próprias, está inserido num contexto social muito particular, em que sua manutenção depende, muitas vezes, de alguma forma de financiamento, para garantir o espaço ou viabilizar especificidades inerentes a esta modalidade artística. 0 presente artigo questiona as formas possíveis de manter a prática de teatro comunitário através das políticas públicas de cultura praticadas no Brasil e principalmente no novo conceito de política pública sociocultural, que são os Pontos de Cultura.

\section{Teatro na Comunidade}

0 foco do teatro feito em contextos comunitários pode estar relacionado com a estética das manifestações culturais e populares e/ou com um conteúdo significativo dos participantes e de sua comunidade. Frequentemente circunscrito a uma condição periférica, o Teatro Comunitário pode constituir uma forma de resistência, que garante a expressão coletiva de um conjunto de ritos, tradições, manifestações populares e histórias próprias da comunidade, celebrando sua identidade, afirmando seus moradores como sujeitos de sua história, gerando a consciência de seus valores e uma consequente noção de cidadania. Narciso Telles compreende a importância da arte como instrumento crítico:

O teatro ganha, além de sua dimensão de educação estética, a dimensão sócio-política por possibilitar o acesso da maioria da população a bens simbólicos restritos apenas às classes dominantes, desencadeando um processo de democratização da cultura e a ampliação da cidadania. (...) A compreensão da importância da arte na formação do indivíduo emancipado, como um instrumento capaz de atuar criticamente em prol da transformação, está presente em todas as ações pedagógicas-teatrais desenvolvidas em comunidades brasileiras.( Telles, 2003, p.66-67)

A trajetória da prática do Teatro em Comunidades envolve, segundo Marcia Pompeo, três modalidades, diferenciadas em função de aplicações de participação mais ou menos hierárquicas. Iniciando com o teatro para as comunidades, com uma abordagem de cima para baixo; teatro com comunidade, aqui o processo é feito mediante consulta sobre os assuntos a serem abordados ou a forma a ser incorporada ao espetáculo; teatro por comunidade inclui as próprias pessoas da comunidade no processo de identificação do tema a ser abordado e envolvimento dos participantes na própria criação teatral. (Nogueira: 2008)

Nessa última abordagem, podemos identificar uma possível retomada do teatro ao seu princípio. Em meio às comemorações populares pelas colheitas, na antiga Grécia, em que o povo celebrava em festa - unindo cânticos e danças com representações de animais e a saga dos seus heróis - e os atores, usando máscaras, submergiam sua personalidade na de outro, enquanto o coro cantava, em 
uníssono, demonstrando a individualidade submetida à função do todo, no louvor a Dionísio, o deus da embriaguez, da fertilidade e do êxtase.

No Brasil, a forma de cortejo do carnaval de escola de samba e de blocos carnavalescos também se enquadram nessa forma popular carregada de história, feita pelo povo, tomando as ruas (hoje, muito restrito a um espaço determinado pelo poder público), numa demonstração de liberdade de expressão e democracia, que integra raças e classes sociais distintas, numa mesma manifestação. 0 interessante é ver a teatralidade popular podendo expressar sua forma própria de cultura, com seus sentidos e sentimentos manifestos, com o povo protagonista de sua própria história, sem uma tradução pelo viés civilizatório da cultura dominante. Augusto Boal tenta retomar a ideia de "reapropriação" do teatro pelo povo:

No princípio, o teatro era o canto ditirâmbico: o povo livre cantando ao ar livre. 0 carnaval. A festa Depois as classes dominantes se apropriaram do teatro e construíram muros divisórios. Primeiro, dividiram o povo, separando atores e expectadores: gente que faz e gente que observa. Terminou-se a festa! Segundo, entre os atores, separou os protagonistas das massas: começou o doutrinamento coercitivo! (Boal, 2010, p.177)

Num contexto político de globalização e veiculação constante nas mídias de uma cultura hegemônica, a afirmação do teatro feito nos contextos comunitários adquire também um cunho político, uma vez que representa vínculos concretos, que são a expressão de valores de subsistência social e podem, dessa forma, se constituir em meios de transformação da realidade. Dessa forma, ele pode ser identificado como próximo do paradigma de mudança social defendido por Bertolt Brecht:

Trata-se de uma atitude crítica. Perante um rio, ela consiste em seu aproveitamento; diante de uma árvore frutífera, em enxertá-la; diante do movimento, nossa atitude crítica consiste em construir veículos e aviões; diante da sociedade, em fazer a revolução. Nossas representações da vida social devem estar destinadas aos técnicos fluviais, aos cuidadores das árvores, aos construtores de veículos e aos revolucionários. Nós os convidamos para que venham aos nossos teatros e lhes pedimos que não se esqueçam de suas ocupações(alegres ocupações), para que nos seja possivel entregar o mundo e nossa visão do mundo às suas mentes e aos seus corações, para que eles modifiquem o mundo ao seu critério. (Brecht,1967, p. 191)

0 Teatro em Comunidade é uma prática realizada em várias partes do mundo, tendo diversas nomenclaturas e modalidades em torno de sua significação. Normalmente tem sua direção nas mãos de um artista profissional que assume a postura de um facilitador. Seu desafio é criar um contexto dialético entre a realidade presente e as possibilidades futuras da comunidade, realizando uma conexão entre a vivência do dia a dia dos participantes e a conjuntura socioeconômica do país e do mundo. "A arte deve levar as contradições até o ponto em que elas fiquem expostas como intoleráveis, uma vez que a contradição intolerável é o motor das mudanças sociais que provocam a quebra da narrativa dominante". (Prentki, 2008, p. 27) 
Estariam todos os artistas profissionais aptos para desenvolver esta tarefa? Paulo Freire nos dá uma pista para a formação desse artista comunitário, sugerindo que ele abra mão da sua postura de condutor solitário do projeto para a de uma pessoa aberta ao diálogo. Isto exige que evite impor-se culturalmente, mas respeite as diferenças. Esta postura representa uma abertura para um conhecimento mútuo e um novo entendimento estético.

Esta prática implica, por isto mesmo, em que o acercamento às massas populares se faça, não para levar-lhes uma mensagem "salvadora", em forma de conteúdo a ser depositado, mas, para em diálogo com elas, conhecer, não só a objetividade em que estão, mas a consciência que tenham dessa objetividade; os vários níveis de percepção de si mesmos e do mundo em que e com que estão. (Freire, 1977, p. 101)

No Brasil, estima-se que a prática de teatro em comunidade seja numerosamente superior ao teatro profissional, embora não haja muitas publicações, pesquisas ou bibliografia a respeito. Através do projeto de pesquisa "Banco de Dados em teatro para o desenvolvimento de comunidades" Marcia Pompeo' identifica seis categorias do Teatro em Comunidade, no Brasil: vinculado a instituições religiosas, geralmente ligado a datas comemorativas; a práticas teatrais em ONGs; em movimentos sociais, como o MST; inserido em projetos de políticas públicas; a partir de iniciativa do teatro de grupo ou de pessoas originárias das próprias comunidades. (NOGUEIRA, 2008). Segundo a autora, estas categorias se interpenetram e não esgotam todas as possibilidades, podendo existir novas formas a serem identificadas e pesquisadas.

\section{Políticas Públicas para o Teatro na Comunidade}

Nestas diferentes modalidades, onde o fazer teatral é fruto da necessidade de comunicação da própria comunidade, de compartilhar os anseios, um tempo-espaço de auto reconhecimento e exercício político, ético e estético, as dificuldades financeiras representam o principal desafio para a continuidade dos trabalhos. Com muita frequência, esse teatro sobrevive exclusivamente da vontade dos participantes, que vêem na coletividade a grande força propulsora para o seu desenvolvimento. Se faltam recursos como formação técnica, recursos para montagem, produção, e circulação, sobra comprometimento e experiência de vida, que estabelece a ética como motor para alavancar os projetos geradores de um teatro vivo, que se pretende verdadeiro em sua interlocução, conteúdo e forma de expressão.

Muitos grupos nascem de oficinas ministradas nas comunidades advindas de programas socioculturais, se articulam e atuam por um determinado tempo, mas não conseguem ultrapassar a barreira financeira e necessitam de incentivos, de criar

1 Marcia Pompeo Nogueira é professora do CEART/UDESC, doutora em drama pela Universidade de Exeter, Inglaterra. 
meios alternativos de sustentabilidade, para que sua prática possa se consolidar. As políticas públicas de cultura teriam aqui um papel fundamental. Elas se caracterizam como programas governamentais com o objetivo de atenuar os desníveis sociais causados pelo sistema econômico, redistribuindo os benefícios sociais, sendo assim compreendidas como responsabilidade do Estado.

Hamilton Faria define Política Pública de Cultura num olhar contemporâneo:

E, assim, chega-se à verdadeira "missão" das políticas públicas de cultura: além de contribuir para a melhoria cultural, a superação da exclusão e de desajustes e da distância cultural entre integrados e excluídos, sua missão também é contribuir verdadeiramente para a gestação de um novo projeto civilizatório centrado no direito à vida em todas as suas manifestações. (Faria, 2003, p.35)

Os grupos oriundos do teatro comunitário, por não estarem legitimados pelo mercado e pela indústria cultural, não conseguem se estabelecer sem essa mão governamental, que pode valorizar esses processos culturais da comunidade, impulsionando a conquista de qualidade de vida associada a esses processos.

Geralmente, após a iniciação teatral e o estímulo à formação de grupos, cria-se uma demanda que as políticas públicas de cultura não conseguem sanar, pois os Editais de cultura são, na grande maioria, voltados a grupos profissionais ou experimentais, que contam com um profissionalismo que os grupos comunitários não possuem. Um abismo é gerado entre a formação e a continuidade de grupos teatrais comunitários, que passam por dificuldades como a falta de espaço, de recursos para montagem e circulação dos trabalhos, bem como para um aprimoramento técnico que possa contribuir para seu desenvolvimento.

Em alguns lugares, por meio de uma organização coletiva, consegue-se gestar projetos e encontrar brechas na legislação de políticas públicas, para o desenvolvimento educativo e social do teatro na comunidade, mas esse coletivismo requer empenho dialógico e dedicação pessoal dos membros do grupo, que se constrói aos poucos, através de muita luta, no envolvimento com o próprio trabalho teatral.

Diante da necessidade de uma política específica que atenda ao desenvolvimento da cultura popular, como forma de potencializar a diversidade, o conceito de Ponto de Cultura² ${ }^{2}$ pode vir a ser uma resposta para a concretização dessas manifestações.

\section{Os Pontos de Cultura}

Ponto de Cultura é um conceito de política pública, que está na base do Programa Nacional de Cultura, Educação e Cidadania - Cultura Viva, de 2004. Foi criado para estimular e fortalecer, no corpo do país, uma rede de criação e gestão cultural.

2 Regulamentado pelas portarias do MinC $n^{\circ} 82$ de 06 de julho de 2004 e 18 de maio de 2005, e é executado pela Secretaria de Cidadania Cultural (SCC). 
São selecionados por meio de editais públicos, criados pelo Ministério da Cultura - MinC - através dos quais organizações culturais da sociedade ganham um reconhecimento institucional, estabelecendo uma parceria com o Estado. As organizações de comunidades na área de cultura, arte, educação, cidadania e economia solidária, depois de selecionadas, recebem $\mathrm{R} \$ 185$ mil reais do Governo Federal (dado/abril 2010), em cinco parcelas semestrais, para potencializar suas ações com a compra de material ou contratação de profissionais, entre outras necessidades.

Inicialmente o Programa era formado através de quatro ações: Escola Viva, em que a escola se transforma no espaço do saber não formal, aberta para a expressão das manifestações culturais da comunidade; Ação Griô, que valoriza o saber ancestral de transmissão oral; Cultura Digital, uma forma de produção e registro da cultura de cada Ponto incorporando a tecnologia, gerando desenvolvimento por aproximação; e Agente Cultura Viva, um investimento em oportunidade de emprego ao jovem da comunidade junto ao Ponto. Todas elas vinculadas aos Pontos de Cultura e articuladas por eles.

Com o passar dos anos e a evolução do Programa, outros prêmios e ações foram concebidos?.

Para participar e receber o recurso, a ação não precisa pertencer a um equipamento cultural do governo, tampouco ser um serviço. Estabelece-se um convênio de gestão compartilhada com objetivo de fortalecer estas iniciativas. Desta forma, esta política cultural representa um novo parâmetro de gestão, baseado numa relação mais aberta entre Estado e sociedade.

o Programa Cultura Viva ganhou nova dimensão com o Programa Mais Cultura, em que a Secretaria de Cidadania e Cultura firmou convênio com 24 estados e 16 municípios para a implantação de redes de Pontos de Cultura (dados de abril/2010), garantindo que os pontos estejam em contato e trocando experiências. A partir daí, a seleção de Pontos de Cultura passou a ser realizada em parceria com os estados ou os municípios e foi possível, além de ampliar o número de Pontos de Cultura pelo território nacional, promover também o compartilhamento dos conceitos e objetivos do Programa junto aos governos locais. («www.cultura.gov.br/culturaviva/s, último acesso em 24/08/2011)

3 Entre eles podemos destacar: o Pontinho de Cultura, visando a produção de cultura infantil; os Pontos de Mídia Livre, mediando a comunicação entre Estado e sociedade de forma livre e autônoma; o Pontão, que articula e difunde as ações em rede; a Teia como um fórum dos Pontos de Cultura; Prêmio Cultura Viva como uma forma de reconhecimento e legitimação; Prêmio Areté, fomentando a troca cultural entre os pontos; Prêmio Txaua, para iniciativas de mobilização e articulação de redes; a Cultura e Saúde, valorizando o conhecimento popular do uso medicinal da natureza; a Cultura da paz, desenvolvendo oficinas e debates contra a violência; a Economia Viva, gerando autonomia financeira e 0 fortalecimento de processos coletivos culturais e a economia em rede. 
0 objetivo do programa tem foco fenomenológico, ao invés de determinar as ações culturais, são as manifestações já existentes que ganham autonomia de ação, de acordo com cada forma particular de organização. É um novo tipo de "poder" compartilhado, que dá condições às iniciativas culturais populares de emancipação do sistema governamental, garantindo o protagonismo e fortalecendo as competências do sujeito.

Essa autonomia gera atos concretos de participação e afirmação social, gerando o que Célio Turino (2009) considera "empoderamento social". Potencializando as iniciativas já em andamento, o Ponto de Cultura cria condições de sustentabilidade na produção da cultura, de forma autônoma e alternativa, quebrando hierarquias e construindo novas legitimidades. (Turino, 2009, p.130)

Desde sua concepção, o Cultura Viva foi pensado para ser desburocratizado e flexível, no sentido de facilitar a inserção das comunidades populares e periféricas nos programas de fomento à cultura, pois são as pessoas que fazem cultura e não o Estado. A este cabe potencializar e conectar as iniciativas da sociedade.

0 objetivo é intensificar a interação entre os sujeitos e seu meio, promovendo um sentido educativo à política pública, deixando a posição de assistencialismo para uma forma cidadã e democrática. Resumidamente, o "Ponto de Cultura pressupõe autonomia e protagonismo sociocultural, potencializados pela articulação em rede e se expressa com o reconhecimento e legitimação do fazer cultural das comunidades, gerando empoderamento social". (Turino, 2007, p. 85)

\section{0s Pontos de Cultura e o Teatro na Comunidade}

Podemos ver nesse Programa uma proposta para a sustentabilidade do teatro comunitário, pois são ações de iniciativa comunitária que se enquadram no perfil dos Pontos de Cultura, criando a possibilidade de desenvolvimento das iniciativas teatrais até a formação de grupos consolidados e centros culturais multiplicadores. Existem hoje mais de 300 Pontos de Cultura no território nacional, essencialmente ligados ao teatro, principalmente comunitário. (〈www.mapasdarede.org.br〉, último acesso em 24/08/2011)

o Ponto de Cultura Piollin, na Paraíba, é um exemplo de espaço de formação e preparação de jovens artistas no qual, segundo Mirthya Guimarães, "o jovem que entra na instituição tem a possibilidade de desenvolver-se enquanto pessoa e artista para, somente em iniciativa futura, completar esse percurso na fundação de um grupo" (Revista Semear Asas, p.34). Torna-se também um desafio preparar esses jovens na gestão de projetos para concorrência de editais públicos e privados, como forma de consolidação e sobrevivência dos grupos. (Guimarães, 2010, p. 34)

Embora o Ponto de Cultura seja um conceito de política pública, é uma tentativa de relacionar movimentos sociais e culturais com arte em comunidades, através de um movimento dialógico de educadores, artistas, gestores articulados coletivamente com a comunidade, isto é, a partir dela. Nesse movimento de união de 
forças e pensamentos, surgem manifestações que vão de encontro às propostas feitas pelo Cultura Viva. Para um dos representantes do movimento nacional dos pontos de cultura, Marcelo das Histórias, os Pontos de Cultura contribuem para a ampliação da base social que discute políticas culturais no Brasil, absorvendo pautas que antes ficavam restritas apenas ao meio artístico. (‘www.pontosdecultura. org.br> último acesso em 24/08/2011)

Em 2010, se encontraram na Colômbia mais de cem redes e organizações socioculturais da América Latina, criando a Plataforma Puente, uma ação mista entre público e sociedade civil para pensar Políticas Públicas Continentais. Segundo Jorge Blandón ${ }^{4}$, o encontro teve ação transformadora:

Buscar reconhecer, compartilhar, dialogar e revitalizar políticas, estratégias, programas e projetos que em toda nossa América tem permitido tecer ações entre o público e o privado, aclarar intenções em torno da cultura e sua transformação social, reconhecer desejos de mulheres $e$ homens por um melhor entorno, tramar sonhos que se fazem de forma cooperativa e estabelecer compromissos de uma nova geração da política, na qual, muitos cidadãos são protagonistas da transformação.(BLANDÓN, J.2010, p.46)

Entre as ideias discutidas, chegou-se a dois pontos principais de articulação: fazer uma campanha continental pela formulação de uma Política Pública de Cultura Viva Comunitária, que se estenda por toda América Latina e fazer valer o direito a cultura em todos os países do território onde se destine $1 \%$ dos pressupostos nacionais para a Cultura Viva, com o objetivo de financiar projetos culturais de origem comunitária e territorial na forma de "Pontos de Cultura", projeto brasileiro do Ministério da Cultura. (ibid, p.46) 0 conceito de Pontos de Cultura parece ir de encontro aos ideais comunitários de arte e cultura, possibilitando um entendimento de fazer cultura como possibilidade natural de manifestação.

Há muitos desafios colocados no Cultura Viva, principalmente ligados a problemas de gestão, pois essa experiência de proximidade entre Estado e sociedade civil é muito recente, resultando num processo de erros e acertos em direção ao entendimento mútuo dessa nova proposta. Com a mudança de governo, gerou-se uma apreensão quanto à continuidade do programa, mas a mobilização social trabalha no sentido de fomentar discussões em reuniões e encontros para ver soluções, desde a regularização de convênios atuais até a criação de novos editais e, principalmente, a transformação do Programa Cultura Viva em Lei Cultura Viva, tornando-o uma política de Estado.

4 Diretor da Corporación Cultural Nuestra Cente, de Medellin, Colômbia e co-fundador da Red Colombiana de Teatro em Comunidade 


\section{Referências Bibliográficas}

$>$ BOAL, Augusto. Teatro do Oprimido e outras poéticas políticas. Rio de janeiro: Civilização Brasileira, 2010.

> BLANDón, J. Teatro é comunidade. Revista Semear Asas, São Paulo, n02, p.43, fevereiro de 2011. Disponível em http://www.pombasurbanas.org.br/revista

> BRECHT, B. Teatro Dialético. Rio de janeiro: Civilização Brasileira, 1967.

> FARIA, Hamilton. "Políticas Públicas de Cultura e Desenvolvimento Humano nas Cidades".In: FREIRE, Paulo .Pedagogia do Oprimido. Rio de Janeiro:Paz e Terra, 1977.BRANT, Leonardo. Políticas Culturais. Barueri, SP: Marole, 2003.

> NOGUEIRA, Marcia Pompeo. “A Opção pelo Teatro nas Comunidades: Alternativas de Pesquisa” In: Urdimento. $\mathrm{N}^{\circ} 10,2008$. $>$ “Teatro em Comunidades." In: FLORENTINO, Adilson; TELLES, Narciso. Cartografias do Ensino de Teatro: das idéias às práticas. Uberlândia: UDUFO, 2008.

> PRENTKI, Tim. "Contra-narrativa: ser ou não ser, esta não é a questão". In: NOGUEIRA, M.P.(org) Teatro na Comunidade: dilemas e possibilidades. Florianópolis: UDESC, 2009.

> TELLES, Narciso. "Teatro Comunitário: Ensino de Teatro e Cidadania". In: Urdimento, No 5, 2003.

> TURIN0, Célio. Ponto de Cultura: 0 Brasil de Baixo para Cima. São Paulo: Anita Garibaldi, 2009.

\section{Sites Pesquisados}

>〈www.mapasdarede.org.br〉 (último acesso 24/08/2011)

$>\langle w w w . p o n t o s d e c u l t u r a . o r g . b r\rangle$ (último acesso 24/08/2011)

> 〈www.cultura.gov.br/culturaviva〉 (último acesso 24/08/2011)

Márcia Pompeo, professora do Departamento de Artes Cênicas/ Centro de Artes da UDESC marciapompeo@gmail.com 